\title{
Psychophysical methodology: Deductions from the phi-gamma hypothesis and related hypotheses
}

\author{
ROBERT M. HERRICK ${ }^{1}$ \\ NAVAL AIR DEVELOPMENT CENTER
}

The phi-gamma hypothesis is a special case of the general hypothesis of a cumulative symmetrical distribution. Assuming any cumulative symmetrical distribution, with stimuli equally spaced about the axis of symmetry, (a) the descending method of limits (DML) threshold distribution is asymmetrical and is a mirror image of the ascending method of limits (AML) threshold distribution; ( $b$ ) the combined method of limits (CML) threshold distribution is symmetrical; ( $c$ ) with the subscripts $A, D$, and $C$ referring to $A M L, D M L$, and $C M L$ distributions: $\boldsymbol{M}_{A}<\boldsymbol{M}_{C}<\boldsymbol{M}_{D} ; \sigma_{A}=\sigma_{D} ; \sigma_{C}>\sigma_{A} ;(d)$ as step size increases: $M_{A}$ increases, $M_{D}$ decreases, $M_{C}$ remains constant, $\sigma_{A}$ and $\sigma_{D}$ increase, $\sigma_{C}$ first decreases and then increases; $(e)$ the mean threshold of the method of constant stimuli (MCS) equals $M_{C}$. For a particular assumption of a cumulative symmetrical distribution, statistical measures of the method of limits can be used to estimate MCS statistics. The analyses are supported by data from brightness discrimination experiments.

The phi-gamma hypothesis and other related hypotheses are commonly used with the Method of Constant Stimuli (MCS). The purpose of this paper is to deduce, from such hypotheses, predictions of the outcome of Method of Limits (ML) experiments.

The model used in deriving the predictions was first invented by Urban (1908). Since Urban's time, the model has been independently reinvented, e.g., by Dixon and Mood (1948), by Herrick (1967), and undoubtedly by others. The model reflects the kind of data obtained in a two-category ("Yes"."No") MCS experiment. In a word, the model assumes that the probability of a "Yes" response increases with an increase in the stimulus intensity.

\section{PSYCHOPHYSICAL PROBABILITY MODEL}

The reader is referred to two earlier publications (Herrick, 1967, 1969) for a full description of the model and for deductions from the model. In this section, only a summary description will be given.

\section{Description of Model}

Assume that equally spaced, increasing stimulus values, $S_{0}, S_{1}$,
$S_{2}, \cdots, S_{n}$, evoke "Yes" responses with increasing probabilities, $\mathrm{p}_{0}, \mathrm{p}_{1}, \mathrm{p}_{2}, \cdots, \mathrm{p}_{\mathrm{n}}$, respectively, and "No" responses with decreasing probabilities, $\mathrm{q}_{0}, \mathrm{q}_{1}, \mathrm{q}_{2}, \cdots, \mathrm{q}_{\mathrm{n}}$, respectively, where $p_{0}+q_{0}=p_{1}+q_{1}=\cdots=p_{n}+q_{n}=1.00$. Also, assume $p_{0}=.00$, i.e., the probability of a "Yes" response at $S_{0}$ is zero, and $p_{n}=1.00$, i.e., the probability of a "Yes" response at $S_{n}$ is 1.00 . The $p$ values will be called MCS $p$ values. (See Table 1.)

\section{Relationships Between MCS p Values and ML Threshold Distributions}

In the ascending method of limits (AML), successive stimuli, $S_{0}, S_{1}, S_{2}$, etc., are presented until a "Yes" response occurs. The probability of the "Yes" occurring at stimulus value $S_{i}$ is $q_{0} q_{1} q_{2}$ $\cdots q_{i-1} p_{i}$ (see Table 1). With $p_{n}=1.00$, the proportion of ascending series terminating at a given stimulus value equals the probability of an ascending series terminating at that value. Thus, of all the ascending series, the proportion terminating at $\mathrm{S}_{4}$ is $q_{0} q_{1} q_{2} q_{3} p_{4}$. For every ascending series terminating at a given stimulus value, the threshold is midway between that value and the preceding value in the series. 3 Thus, an ascending series that terminates at $S_{4}$ yields a threshold of $\left(S_{3}+S_{4}\right) / 2$ or $k_{4}$.

Similar considerations applied to the descending method of limits (DML) lead to the conclusion that the proportion of descending series terminating at, say, $S_{4}$ in the Table 1 example, is $p_{8} p_{7} p_{6} p_{5} q_{4}$, and for every descending series that terminates at $S_{4}$, the resulting threshold is $\left(S_{4}+S_{5}\right) / 2$ or $k_{5}$.

Combining the AML threshold distribution with the DML threshold distribution gives the threshold distribution of the combined method of limits (CML).

\section{Summary Statistical Measures of ML Distributions}

The mean threshold of the AML threshold distribution is:

$$
M_{A}=k_{0}+c\left(1+q_{1}+q_{1} q_{2}+q_{1} q_{2} q_{3}+\cdots+q_{1} q_{2} \cdots q_{n-1}\right),
$$

where $c$ is the step size, i.e., $c=\left(S_{n}-S_{n-1}\right)=\cdots=\left(S_{2}-S_{1}\right)=$ $\left(S_{1}-S_{0}\right)$, and $k_{0}=\left(S_{0}-c / 2\right)$.

The mean threshold of the DML threshold distribution is:

Table 1

Derivation of Method of Limits Thresholds from Method of Constant Stimuli (MCS) p Values on Assumption that MCS Distribution is a Cumulative Symmetrical Distribution

\begin{tabular}{|c|c|c|c|c|c|c|}
\hline \multirow{3}{*}{$\begin{array}{l}\text { Stimulus } \\
\text { Value } \\
S_{0}\end{array}$} & \multirow{2}{*}{\multicolumn{2}{|c|}{$\frac{\text { Method of Constant Stimuli }}{\text { Proportion of Responses }}$}} & \multirow{2}{*}{\multicolumn{2}{|c|}{$\begin{array}{c}\text { Ascending Method of Limits } \\
\begin{array}{c}\text { Probability of series terminating } \\
\text { at given stimulus value }\end{array}\end{array}$}} & \multirow{2}{*}{\multicolumn{2}{|c|}{$\begin{array}{c}\text { Descending Method of Limits } \\
\text { Probability of series terminating } \\
\text { at given stimulus value }\end{array}$}} \\
\hline & & & & & & \\
\hline & $\mathrm{p}_{0}=.00$ & "No" & $\mathbf{p}_{0}$ & $=\mathbf{p}_{\mathbf{0}}$ & $\mathbf{p}_{8} \mathbf{p}_{7} \ldots \mathbf{p}_{1} \mathbf{q}_{0}$ & $=\mathbf{p}_{8} \mathbf{p}_{7} \ldots \mathbf{p}_{1}\left(\mathbf{p}_{8}\right)$ \\
\hline $\mathbf{S}_{1}$ & $\mathrm{p}_{1}$ & $\mathrm{q}_{1}$ & $\mathrm{q}_{0} \mathrm{p}_{1}$ & $=p_{8}\left(p_{1}\right)$ & $\mathbf{p}_{8} \mathbf{p}_{7} \ldots \mathbf{p}_{2} q_{1}$ & $=\mathrm{p}_{8} \mathrm{p}_{7} \ldots \mathrm{p}_{2}\left(\mathrm{p}_{7}\right)$ \\
\hline $\mathrm{S}_{2}$ & $\mathrm{p}_{2}$ & $q_{2}$ & $q_{0} q_{1} p_{2}$ & $=\mathrm{p}_{8} \mathrm{p}_{7}\left(\mathrm{p}_{2}\right)$ & $\mathrm{p}_{8} \mathrm{p}_{7} \ldots \mathrm{p}_{3} \mathrm{q}_{2}$ & $=p_{8} p_{7} \ldots p_{3}\left(p_{6}\right)$ \\
\hline $\mathbf{S}_{3}$ & $\mathbf{p}_{3}$ & 93 & $q_{0} q_{1} q_{2} p_{3}$ & $=p_{8} p_{7} p_{6}\left(p_{3}\right)$ & $p_{8} p_{7} \ldots p_{4} q_{3}$ & $=p_{8} p_{7} \cdots p_{4}\left(p_{5}\right)$ \\
\hline$S_{4}$ & P4 & $q_{4}$ & $q_{0} q_{1} q_{2} q_{3} p_{4}$ & $=\mathrm{p}_{8} \mathrm{p}_{7} \mathrm{p}_{6} \mathrm{p}_{5}\left(\mathrm{p}_{4}\right)$ & $\mathrm{P}_{8} \mathrm{P}_{7} \mathrm{P}_{6} \mathrm{P}_{5} \mathrm{q}_{4}$ & $=\mathbf{p}_{8} \mathbf{p}_{7} \cdots \mathbf{p}_{5}\left(\mathbf{p}_{4}\right)$ \\
\hline $\mathrm{S}_{\mathrm{S}}$ & p5 & $\mathrm{q}_{5}$ & $\mathrm{q}_{0} \mathrm{q}_{1} \ldots \mathrm{q}_{4} \mathrm{p}_{5}$ & $=\mathrm{p}_{8} \mathrm{p}_{7} \cdots \mathrm{p}_{4}\left(\mathrm{p}_{5}\right)$ & $\mathrm{P}_{8} \mathrm{p}_{7} \mathrm{P}_{6} \mathrm{q}_{5}$ & $=p_{8} p_{7} p_{6}\left(p_{3}\right)$ \\
\hline$S_{6}$ & P6 & $q_{6}$ & $\mathrm{q}_{0} \mathrm{q}_{1} \ldots \mathrm{q}_{5} \mathrm{P}_{6}$ & $=p_{8} p_{7} \cdots p_{3}\left(p_{6}\right)$ & $\mathrm{p}_{8} \mathrm{p}_{7} \mathrm{q}_{6}$ & $=\mathrm{p}_{8} \mathrm{p}_{7}\left(\mathrm{p}_{2}\right)$ \\
\hline$S_{7}$ & $\mathrm{p}_{7}$ & $q_{7}$ & $\mathrm{q}_{0} \mathrm{q}_{1} \ldots \mathrm{q}_{6} \mathrm{p}_{7}$ & $=\mathrm{p}_{8} \mathrm{p}_{7} \cdots \mathrm{p}_{2}\left(\mathrm{p}_{7}\right)$ & $\mathrm{P}_{8} \mathrm{q}_{7}$ & $=\mathrm{p}_{8}\left(\mathrm{p}_{1}\right)$ \\
\hline$S_{8}$ & $\mathbf{p}_{8}=1.00$ & 98 & $q_{0} q_{1} \ldots q_{7} p_{8}$ & $=\mathrm{p}_{8} \mathrm{p}_{7} \ldots \mathrm{p}_{1}\left(\mathrm{p}_{8}\right)$ & 98 & $=\mathbf{p}_{0}$ \\
\hline
\end{tabular}



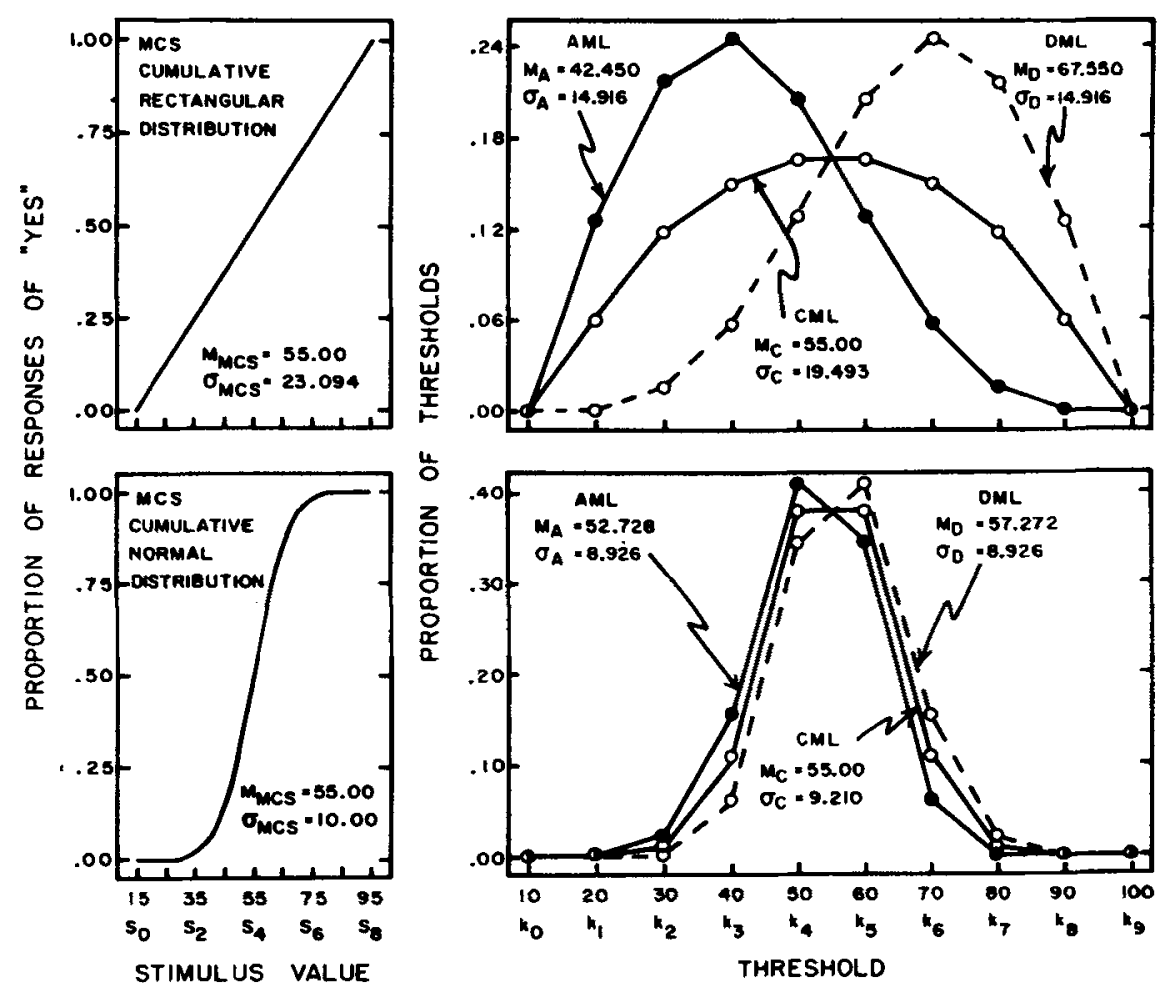

Fig. 1. Derivation of ascending method of limits (AML), descending method of limits (DML), and combined method of limits (CML) threshold distributions from $p$ values representing the quantal hypothesis (upper) and the phi-gamma hypothesis (lower). Hypothetical data.

$$
\begin{aligned}
M_{D}=k_{0} & +\alpha\left(n-p_{n-1}-p_{n-1} p_{n-2}-p_{n-1} p_{n-2} p_{n-3}\right. \\
& \left.-\cdots-p_{n-1} p_{n-2} p_{n-3} \cdots p_{2} p_{1}\right) .
\end{aligned}
$$

The mean threshold for the CML threshold distribution, when the number of thresholds of the AML distribution, namely, $N_{A}$, equals the number of thresholds of the DML distribution, namely, $\mathbf{N}_{\mathbf{D}}$, is:

$$
M_{C}=\left(M_{A}+M_{D}\right) / 2
$$

No matter what set of MCS p values are assumed,

$$
\mathbf{M}_{\mathbf{D}}>\mathbf{M}_{\mathrm{C}}>\mathbf{M}_{\mathrm{A}}
$$

The standard deviation of the AML threshold distribution is:

$o_{A}=\left\{c^{2}\left[1+3 q_{1}+5 q_{1} q_{2}+7 q_{1} q_{2} q_{3}\right.\right.$

$$
\left.\left.+\cdots+(2 n-1) q_{1} q_{2} \cdots q_{n-1}\right]-\left(M_{A}-k_{0}\right)^{2}\right\}^{1 / 2} .
$$

The standard deviation of the DML threshold distribution is:

$$
\begin{aligned}
\sigma_{D}= & \left\{c ^ { 2 } \left[n^{2}-3 p_{n-1} p_{n-2} \cdots p_{1}-5 p_{n-1} p_{n-2} \cdots p_{2}\right.\right. \\
& \left.-7 p_{n-1} p_{n-2} \cdots p_{3}-\cdots-(2 n-1) p_{n-1}\right] \\
& \left.-\left(M_{D}-k_{0}\right)^{2}\right\}^{1 / 2}
\end{aligned}
$$

When $\mathbf{N}_{A}=\mathbf{N}_{\mathbf{D}}$, the standard deviation for the CML threshold distribution is:

$$
\sigma_{C}=\left\{\left[\left(M_{A}-M_{D}\right) / 2\right]^{2}+\left(\sigma_{A}^{2}+\sigma_{D}^{2}\right) / 2\right\}^{1 / 2}
$$

\section{CUMULATTVE SYMMETRICAL DISTRIBUTIONS}

\section{Definition of Cumulative Symmetrical Distribution}

Consider a distribution, $y=f(x)$. If, with respect to some $x$ value, $x_{0}, f\left(x_{0}-\Delta x\right)=f\left(x_{0}+\Delta x\right)$ for any value of $\Delta x$, the equation is an equation of a symmetrical distribution. When the ordinates of such a distribution are cumulated, the resulting distribution is a cumulative symmetrical distribution. The left half of Fig. 1 illustrates two cumulative symmetrical distributions, each symmetrical with respect to the stimulus value, 55 .

If the ordinate of a cumulative symmetrical distribution at $\left(x_{0}-\Delta x\right)$ is $p_{i}$, the ordinate at $\left(x_{0}+\Delta x\right)$ is $\left(1-p_{j}\right)$ or $q_{i j}$. Now, with respect to the probability model described above, if stimulus values for the ML are selected with respect to the axis of symmetry, $p_{0}=q_{n}, p_{1}=q_{n-1}, p_{2}=q_{n-2}, \cdots, p_{n-1}=q_{1}$, $p_{n}=q_{0}$.

\section{Summary Statistics of Cumulative Symmetrical Distribution}

With MCS $p$ values selected with respect to the axis of symmetry, the middlemost stimulus must have an associated $p=0.50$. In the left half of Fig. 1, for example, the middlemost stimulus is $\mathrm{S}_{4}$, so $\mathrm{p}_{4}$ must equal 0.50 . With an even number of stimuli, the two middlemost stimuli must have associated $p$ values that fall equally above and below 0.50 . Since the stimulus value associated with $p=0.50$ is the mean (or median) threshold of the MCS, the mean (or median) threshold of the MCS is always midway between $S_{0}$ and $S_{n}$. That is:

$$
M_{M C S}=\left(S_{0}+S_{n}\right) / 2 \text {. }
$$

The variability of a cumulative symmetrical distribution may be specified by the standard deviation of the distribution. The symbol for this measure will be $\sigma_{\mathrm{MC}} s$.

\section{Assumptions of Cumulative Symmetrical Distributions in Psychophysics}

Two assumptions commonly made in psychophysics are (a) the phi-gamma hypothesis, which states that, as a function of increasing stimulus intensity, the proportions of "Yes" responses, i.e., the MCS $\mathrm{p}$ values, are described by a cumulative normal 
distribution, and (b) the quantal hypothesis, which states that the $p$ values form a cumulative rectangular distribution (Guilford, 1954). Both of these hypotheses may be subsumed under the hypothesis that the $p$ values form a cumulative symmetrical distribution. Thus, any deductions from the probability model that apply to a cumulative symmetrical distribution will apply to the phi-gamma hypothesis, to the quantal hypothesis, and to any other hypothesis that assumes a cumulative symmetrical distribution.

\section{DEDUCTIONS BASED ON THE ASSUMPTION THAT THE MCS p VALUES FORM A CUMULATIVE SYMMETRICAL DISTRIBUTION}

\section{Shapes of ML Distributions}

In Table 1 , the proportion of ascending series terminating at $S_{3}$ is $q_{0} q_{1} q_{2} p_{3}$. In a cumulative symmetrical distribution, with nine stimuli, $q_{0}=p_{8}, q_{1}=p_{7}, q_{2}=p_{6}$, etc. Therefore, $q_{0} q_{1} q_{2} p_{3}=$ $p_{8} p_{7} p_{6} p_{3}$, as indicated in Table 1 . Similarly, the proportion of descending series terminating at each stimulus value may be expressed in terms containing only $p$ values, as in Table 1. A comparison of the proportions of AML series terminating at the different stimulus values with the proportions of DML series terminating at the different stimulus values indicates correspondence. For the Table 1 data, the proportions of ascending series terminating at $S_{0}, S_{1}, S_{2}, \cdots, S_{8}$ equal the proportions of descending series terminating at $S_{8}, S_{7}, S_{6}, \cdots$, $S_{0}$, respectively. Thus, the proportions of AML thresholds of values $k_{1}, k_{2}, k_{3}, \cdots, k_{8}$ equal the proportions of DML thresholds of values $\mathrm{k}_{8}, \mathrm{k}_{7}, \mathrm{k}_{6}, \cdots, \mathrm{k}_{1}$, respectively. In short, the $D M L$ threshold distribution is a mirror image of the AML threshold distribution.
To be symmetrical, an AML threshold distribution must have equal ordinate values at points equally distant from an axis of symmetry. For example, with respect to Table 1, the proportion of AML thresholds of value $k_{1}$ must equal the proportion of AML thresholds of value $\mathbf{k}_{\mathbf{8}}$. Now, the proportion of AML thresholds of value $k_{1}$ is $q_{0} p_{1}=(1.00) p_{1}=p_{1}$, and the proportion of $A M L$ thresholds of value $k_{8}$ is $p_{1} p_{2} p_{3} p_{4} p_{5} p_{6} p_{7}\left(p_{8}\right)^{2}$. Thus, the proportions at $k_{1}$ and $k_{8}$ are unequal. Therefore, an $A M L$ threshold distribution is asymmetrical. Since a DML distribution is a mirror image of an AML distribution, it too must be asymmetrical.

The above analysis indicates that the assumption that MCS $p$ values form a cumulative symmetrical distribution is incompatible with the assumption of normality, or of any other form of symmetry, for the AML or DML threshold distributions. Conversely, if either the AML or the DML threshold distribution is symmetrical, MCS p values cannot form points on a cumulative symmetrical distribution. ${ }^{4}$

By pooling the AML and DML distributions, the threshold distribution of the CML is obtained. For the CML threshold distribution, the proportion of thresholds of value $k_{1}$ (see Table 1) is $\left(q_{0} p_{1}+p_{8} p_{7} \cdots p_{1} q_{0}\right) / 2$. The proportion of thresholds of value $k_{8}$ is the same. Similarly, the proportion of thresholds of value $k_{2}$ equals the proportion of thresholds of value $\mathrm{k}_{7}$, etc. Thus, the $C M L$ threshold distribution is symmetrical.

If a CML distribution, expressed in proportions of thresholds, is cumulated, is the result identical with the underlying cumulative symmetrical distribution of $p$ values? For example, if the $\mathrm{CML}$ distribution of Fig. 1 , with $\mathrm{M}_{\mathrm{C}}=55.00$ and $\sigma_{\mathrm{C}}=9.210$, is cumulated, is the plot the same as the plot of the MCS p values

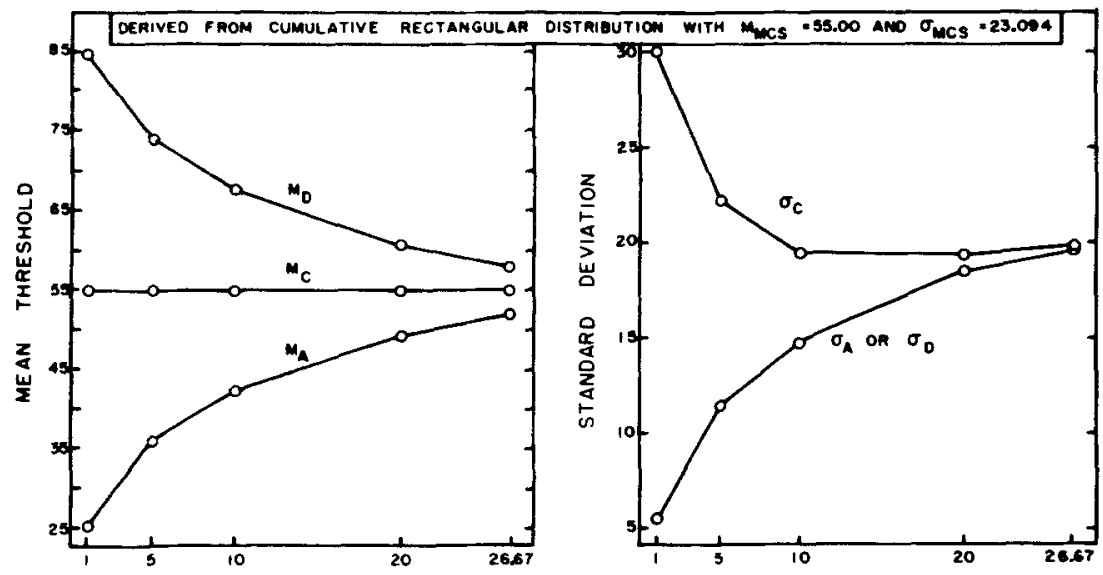

Fig. 2. Means and standard deviations of method of limits threshold distributions as a function of step size. Subscripts refer to ascending method of limits (A), descending method of limits (D), and combined me. thod of limits (C).

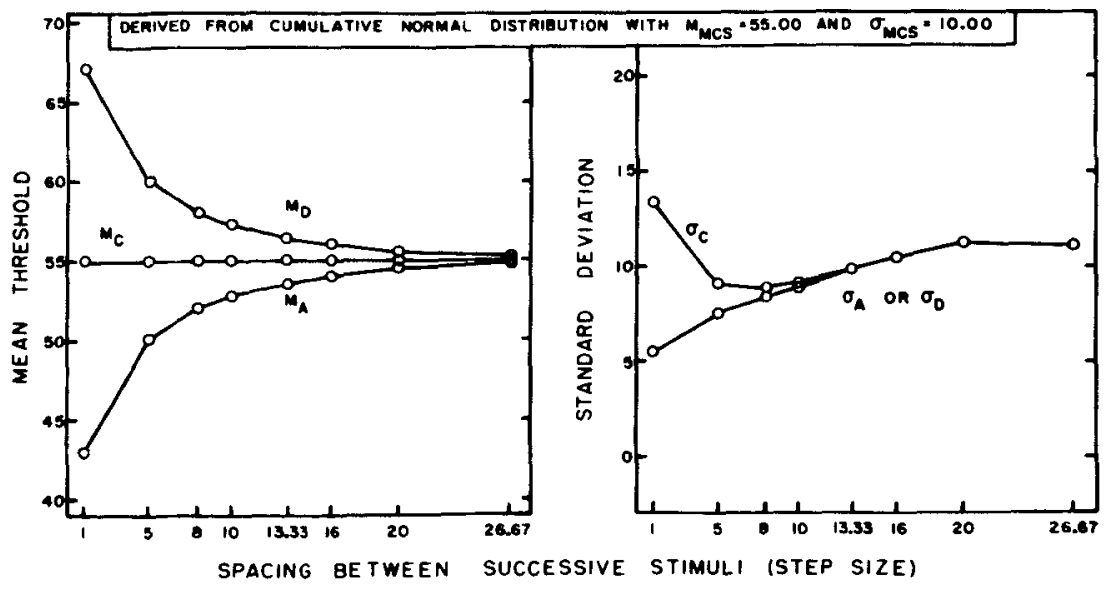


with $\mathrm{M}_{\mathrm{MCS}}=55.00$ and $\sigma_{\mathrm{MCS}}=10.00$ ? Obviously not, in the Fig. 1 example. Moreover, analyses given elsewhere (Herrick, 1968) indicate that, in general, a cumulated CML distribution is not equivalent to the associated MCS p values. Siegel (1962) assumed such equivalence in his comparison of psychophysical methods.

\section{Mean Thresholds of ML Distributions}

Equation 1 gave a description of $M_{A}$ for any set of MCS $p$ values. Equation 1 may also be written as

$$
\mathbf{M}_{\mathrm{A}}=\mathrm{S}_{0}+\mathrm{cz}
$$

where $\mathrm{z}=.5+\mathrm{q}_{1}+\mathrm{q}_{1} \mathrm{q}_{2}+\mathrm{q}_{1} \mathrm{q}_{2} \mathrm{q}_{3}+\cdots+\mathrm{q}_{1} \mathrm{q}_{2} \cdots \mathrm{q}_{\mathrm{n}-1}$. Similarly,

$$
M_{D}=S_{n}-c z
$$

Substituting, in Eq. 3, the values for $\mathrm{M}_{\mathrm{A}}$ and $\mathrm{M}_{\mathrm{D}}$ given in Eqs. 9 and 10:

$$
M_{C}=\left(S_{0}+c z+S_{n}-c z\right) / 2=\left(S_{0}+S_{n}\right) / 2
$$

Equation 11 indicates that the phi-gamma hypothesis, the quantal hypothesis, or any hypothesis of a cumulative symmetrical distribution predicts the same $M_{C}$.

Subtracting Eq. 9 from Eq. 10 gives the amount by which $M_{D}$ is greater than $\mathbf{M}_{\mathbf{A}}$ :

$$
M_{D}-M_{A}=c(n-2 z)=\text { Range }-2 c z .
$$

\section{Standard Deviations of ML Distributions}

When distributions are mirror images, their standard deviations are equal. ${ }^{5}$ Therefore, $\sigma_{A}=\sigma_{D}$.

Since $\sigma_{A}=\sigma_{D}, \sigma_{A}$ may be substituted for $\sigma_{D}$ in Eq. 7. When the terms are rearranged:

$$
\sigma_{C}^{2}-\sigma_{A}^{2}=\left[\left(M_{A}-M_{D}\right) / 2\right]^{2} .
$$

Influence of Step Size on ML Mean Thresholds and Standard Deviations

In the examples of Fig. 1, the spacing between successive stimuli is 10 units, i.e., $\mathrm{c}=10$. The derivation of ML distributions from MCS p values was also carried out for other step sizes for the cumulative rectangular and cumulative normal distributions of Fig. 1. In all cases, $S_{0}=15$. The largest step size used, 26.667, was obtained by dividing the range by 3 , i.e., $(95-15) \div 3=26.667$. This gives $S_{0}=15, S_{1}=41.667$, $S_{2}=68.333, S_{4}=95$. If the range were divided in to larger steps, e.g., by dividing the range by 2 , the result would be the trivial case of only three stimuli, 15,55 , and 95 , with associated $p$ values of $.00, .50$, and 1.00 . (Note that when stimuli are selected with respect to the axis of symmetry, c can only equal the values obtained by dividing the range by integers.)

In general, the number of stimulus values covering the range from $S_{0}$ through $S_{n}$, may be computed by:

Number of stimulus values $=\left[\left(S_{n}-S_{0}\right) / c\right]+1=($ Range $/ c)+1$.

The $\mathrm{p}$ values used with the cumulative rectangular distribution were derived by calculation. The $p$ values used with the cumulative normal distribution were obtained from a normal curve table.

For the ML distributions derived with the different step sizes, the means and standard deviations computed are plotted in Fig. 2.

\section{ESTIMATION OF MMCS AND $\sigma_{M}$ CS FROM ML MEASURES ON THE ASSUMPTION OF A CUMULATIVE NORMAL DISTRIBUTION}

In this section, relationships concerning only the phi-gamma hypothesis will be considered.

\section{Estimation of $\mathbf{M}_{\mathbf{M}} \mathrm{CS}$}

Dividing a ML term by $\sigma_{\mathrm{MCs}}$ expresses the ML term in units of $\sigma_{\mathrm{MCS}}$. In what follows, when a ML term is expressed in units of $\sigma_{\mathrm{MCS}}$, the term will carry a prime. For example, $\left(\mathrm{c} / \sigma_{\mathrm{MCS}}\right)=\mathrm{c}^{\prime}$; $\left(M_{A} / \sigma_{M C S}\right)=M_{A}^{\prime}$.

A particular stimulus value may be expressed in terms of $\mathrm{M}_{\mathrm{MCS}}$ and $\sigma_{\mathrm{MCS}}$. For example, for the cumulative normal distribution of Fig. 1, the stimulus value $S_{0}$ may be expressed as $\mathrm{M}_{\mathrm{MCS}}-4 \sigma_{\mathrm{MCS}}$.

With the above points in mind, consider Eq.9. When $\left(\mathrm{M}_{\mathrm{MCS}}-4 \sigma_{\mathrm{MCS}}\right)$ is substituted for $S_{0}$, and each term is divided by $\sigma_{\mathrm{MCS}}$ :

$$
M_{A}^{\prime}=\left(M_{M C S}^{\prime}-4\right)+c^{\prime} z \text {. }
$$

Now, for the assumption of a cumulative normal distribution, the relationship between $\mathrm{z}$ and $\mathrm{c}^{\prime}$, for $\mathrm{c}^{\prime}$ values between 0.5 and 2.0 , is approximately described by: ${ }^{6}$

$$
\mathrm{z}=.181+\left(3.592 / \mathrm{c}^{\prime}\right)
$$

Substituting this value for $\mathrm{z}$ in Eq. 15, and multiplying by $\sigma_{\mathrm{MCS}}$ gives:

$$
\mathrm{M}_{\mathrm{A}}=\mathrm{M}_{\mathrm{MCS}}-.408 \sigma_{\mathrm{MCS}}+.181 \mathrm{c} .
$$

In the following section, Eq. 21 relates $\sigma_{M C S}, \sigma_{A}$, and $c$. Substituting in Eq. 17 the value of $\sigma_{\mathrm{MCS}}$ given in Eq. 21, and solving for $\mathrm{M}_{\mathrm{MCS}}$,

$$
\mathrm{M}_{\mathrm{MCs}}=\mathrm{M}_{\mathrm{A}}+.637 \sigma_{\mathrm{A}}-.337 \mathrm{c} .
$$

Similarly,

$$
\mathrm{M}_{\mathrm{MCS}}=\mathrm{M}_{\mathrm{D}}-.637 \sigma_{\mathrm{D}}+.337 \mathrm{c} \text {. }
$$

The value of $\mathbf{M}_{\mathrm{MCS}}$ may also be estimated by $\mathbf{M}_{C}$, for $\mathrm{M}_{\mathrm{MCS}}=$ $\left(S_{n}-S_{0}\right) / 2=M_{C}$.

\section{Estimation of $\sigma_{\mathrm{MCS}}$}

For the assumption of a cumulative normal distribution, for $\mathbf{c}^{\prime}$ values between 0.5 and 2.0 , the approximate relationship 7 between $c^{\prime}$ and $\sigma_{\mathrm{A}}^{\prime}$ is:

$$
\sigma_{\mathrm{A}}^{\prime}=.641+.245 \mathrm{c}^{\prime}
$$

Multiplying Eq. 20 by $\sigma_{\mathrm{MCS}}$ and solving for $\sigma_{\mathrm{MCS}}$ :

$$
\sigma_{\mathrm{MCS}}=1.56 \sigma_{\mathrm{A}}-.382 \mathrm{c} \text {. }
$$

Also, since $\sigma_{A}=\sigma_{D}$,

$$
\sigma_{\mathrm{MCS}}=1.56 \sigma_{\mathrm{D}}-.382 \mathrm{c} \text {. }
$$

Substituting in Eq. 13 the values for $\mathrm{M}_{\mathrm{A}}, \mathrm{M}_{\mathrm{D}}$, and $\sigma_{\mathrm{A}}$ given above, and solving for $\sigma_{\mathrm{MCS}}$, gives an estimate of $\sigma_{\mathrm{MCS}}$ in terms of $\sigma_{\mathrm{C}}$ and $\mathrm{c}$ :

Comment

$$
\sigma_{\mathrm{MCS}}=(-.144 \mathrm{c})+\left(2.31 \sigma_{\mathrm{C}}^{2}-.187 \mathrm{c}^{2}\right)^{1 / 2} / 1.155 .
$$

It should be noted that the differences between ML and MCS 
Table 2

Summary of Experimental Procedures

\begin{tabular}{|c|c|c|c|}
\hline Observer & Session & Procedure & Log $\Delta \mathrm{l}$ Luminances $(\mathrm{mL})$ Used \\
\hline \multicolumn{4}{|c|}{ Experiment 1} \\
\hline A.L. & $\begin{array}{l}\text { A.M. } \\
\text { P.M. }\end{array}$ & $\begin{array}{l}\text { AML } \\
\text { DML } \\
\text { AML } \\
\text { DML }\end{array}$ & $\begin{array}{l}-.37,-.34,-.31,-.28, \text { etc. } \\
-.19,-.22,-.25,-.28 \text {, etc. } \\
-.34,-.31,-.28,-.25 \text {, etc. } \\
-.16,-.19,-.22,-.25 \text {, etc. }\end{array}$ \\
\hline J.D. & $\begin{array}{l}\text { A.M. } \\
\text { P.M. }\end{array}$ & $\begin{array}{l}\text { AML } \\
\text { DML } \\
\text { AML } \\
\text { DML }\end{array}$ & $\begin{array}{l}-.58,-.52,-.46,-.40 \text {, etc. } \\
-.22,-.28,-.34,-.40 \text {, etc. } \\
-.76,-.70,-.64,-.58 \text { etc. } \\
-.04,-.10,-.16,-.22 \text {, etc. }\end{array}$ \\
\hline \multicolumn{4}{|c|}{ Experiment 2} \\
\hline A.L. & A.M. & $\begin{array}{l}\text { DML } \\
\text { (lange step) } \\
\text { DML } \\
\text { (small step) } \\
\text { DML } \\
\text { (large step) } \\
\text { DML } \\
\text { (small step) }\end{array}$ & $\begin{array}{l}-.04,-.10,-.16,-.22 \text {, etc. } \\
-.04,-.055,-.07,-.085 \text {, etc. } \\
-.10,-.16,-.22,-.28, \text { etc. } \\
-.10,-.115,-.13,-.145 \text {, etc. }\end{array}$ \\
\hline J.D. & A.M. & $\begin{array}{l}\text { DML } \\
\text { (large step) } \\
\text { DML } \\
\text { (small step) } \\
\text { DML } \\
\text { (large step) } \\
\text { DML } \\
\text { (small step) }\end{array}$ & $\begin{array}{l}-.04,-.16,-.28,-.40, \text { etc. } \\
-.04,-.07,-.10,-.13 \text {, etc. } \\
-.16,-.28,-.40,-.52 \text {, etc. } \\
-.16,-.19,-.22,-.25 \text {, etc. }\end{array}$ \\
\hline \multicolumn{4}{|c|}{ Experiment 3} \\
\hline A.L. & $\begin{array}{l}\text { A.M. \& } \\
\text { P.M. } \\
\text { A.M. \& } \\
\text { P.M. }\end{array}$ & $\begin{array}{l}\text { MCS } \\
\text { DML } \\
\text { MCS } \\
\text { DML } \\
\end{array}$ & $\begin{array}{l}-.34,-.28,-.22 \text {, and }-.16 \\
-.16,-.175,-.19,-.205 \text {, etc. } \\
-.52,-.40,-.28, \text { and }-.16 \\
-.16,-.19,-.22,-.25 \text {, etc. } \\
\end{array}$ \\
\hline
\end{tabular}

statistical measures are quite small. For example, stating the differences in terms of $\sigma_{M C S}$, when $c^{\prime}=1.0:\left(\mathbf{M}_{M C S}-M_{A}\right)<$ $\left(.25 \sigma_{\mathrm{MCS}}\right),\left(\sigma_{\mathrm{MCS}}-\sigma_{\mathrm{A}}\right)<\left(.11 \sigma_{\mathrm{MCS}}\right)$, and $\left(\sigma_{\mathrm{MCS}}-\sigma_{\mathrm{C}}\right)<$ $\left(.08 \sigma_{\mathrm{MCS}}\right)$. When $\mathrm{c}^{\prime}=1.6:\left(\mathrm{M}_{\mathrm{MCS}}-\mathrm{M}_{\mathrm{A}}\right)<\left(.11 \sigma_{\mathrm{MCS}}\right)$, $\left(\sigma_{\mathrm{A}}-\sigma_{\mathrm{MCS}}\right)<\left(.05 \sigma_{\mathrm{MCS}}\right)$, and $\left(\sigma_{\mathrm{C}}-\sigma_{\mathrm{MCS}}\right)<\left(.05 \sigma_{\mathrm{MCS}}\right)$.

\section{Practical Problems}

\section{EXPERIMENTAL EVALUATIONS}

Although the above analyses provide many predictions, experimental evaluation is difficult because of practical considerations. First, since only a limited number of judgments may be obtained in an experimental session, the resulting sample statistics will be somewhat unreliable. Second, a predicted difference is often quite small. Third, in selecting stimuli for a ML experiment, the axis of symmetry for the cumulative symmetrical distribution is unknown. Thus, the stimuli will not be spaced with respect to the axis of symmetry, and, consequently, the predictions given above will not hold exactly. Fourth, in an attempt to obtain many thresholds for a given number of judgments, the initial stimulus in a ML series may be selected within the appropriate range of stimuli, rather than at the extreme of the range. For example, the initial stimulus for a descending series may be one with an associated $p$ value of, say, 0.92 , rather than 1.00 . Such selections would yield differences between statistical measures that were less than the differences predicted by the analyses. Keeping these problems in mind, we turn now to some brightness discrimination experiments designed to evaluate some of the gross predictions of the analyses.

\section{Procedure}

The experimental situation was as follows. Monocularly, an $\mathrm{O}$ centrally fixated a circular adapting field of white light, $1 \mathrm{deg}$ $7 \mathrm{~min}$ in diam, at an apparent distance of $570 \mathrm{~mm}$, with a luminance of $11.5 \mathrm{~mL}$. On command, a $20-\mathrm{msec}$ flash (the $\Delta \mathrm{l}$
Table 3

Experiment 1. Results of Brightness Discrimination Experiments Using the AML and the DML. [Predictions from Analyses: $M_{A}<M_{C} ; M_{C}<M_{D}$; $\left.\sigma_{A}=\sigma_{D} ; \sigma_{C}>\sigma_{A} ; \sigma_{C}>\sigma_{D} \cdot\right]$

\begin{tabular}{|c|c|c|c|c|c|c|c|}
\hline \multirow{2}{*}{ 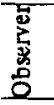 } & \multirow[b]{2}{*}{ Session } & \multicolumn{6}{|c|}{ Statistical Measure in $\log \mathrm{mL}$} \\
\hline & & $\mathbf{M}_{\mathbf{A}}$ & $\mathbf{M}_{\mathbf{D}}$ & $\mathbf{M}_{\mathbf{C}}$ & $\sigma_{\mathbf{A}}$ & $\sigma_{\mathrm{D}}$ & $\sigma_{\mathrm{C}}$ \\
\hline A.L. & $\begin{array}{l}\text { A.M. } \\
\text { P.M. }\end{array}$ & $\begin{array}{l}-.278 \\
-.279\end{array}$ & $\begin{array}{l}-.255 \\
-.216\end{array}$ & $\begin{array}{l}-.267 \\
-.225\end{array}$ & $\begin{array}{l}.044 \\
.043\end{array}$ & $\begin{array}{l}.038 \\
.038\end{array}$ & $\begin{array}{l}.042 \\
.051\end{array}$ \\
\hline J.D. & $\begin{array}{l}\text { A.M. } \\
\text { P.M. }\end{array}$ & $\begin{array}{l}-.474 \\
-.526\end{array}$ & $\begin{array}{l}-.402 \\
-.268\end{array}$ & $\begin{array}{l}-.443 \\
-.399\end{array}$ & $\begin{array}{l}.073 \\
.114\end{array}$ & $\begin{array}{l}.064 \\
.152\end{array}$ & $\begin{array}{l}.077 \\
.186\end{array}$ \\
\hline
\end{tabular}

Table 4

Experiment 2. Results of Brightness Discrimination Experiments Uring Two Step Sizes with the Descending Method of Limite. [Predictions from Analyses: $M_{D}$ (large step) $<M_{D}$ (small step); $\sigma_{\mathrm{D}}$ (large step) $>\sigma_{\mathrm{D}}$ (amall step).]

\begin{tabular}{rccccc}
\hline & & \multicolumn{4}{c}{ Statistical Measure in Log mL } \\
\cline { 3 - 6 } Observer & Session & $\begin{array}{c}\mathrm{M}_{\mathrm{D}} \\
\text { (large } \\
\text { step) }\end{array}$ & $\begin{array}{c}\text { MD } \\
\text { (small } \\
\text { step) }\end{array}$ & $\begin{array}{c}\sigma_{\mathrm{D}} \\
\text { (large } \\
\text { step) }\end{array}$ & $\begin{array}{c}\sigma_{\mathrm{D}} \\
\text { (small } \\
\text { step) }\end{array}$ \\
\hline \multirow{2}{*}{ A.L. } & A.M. & -.200 & -.168 & .060 & .033 \\
& P.M. & -.217 & -.156 & .047 & .031 \\
J.D. & A.M. & -.379 & -.344 & .093 & .093 \\
& P.M. & -.359 & -.240 & .129 & .076 \\
\hline
\end{tabular}

Table 5

Experiment 3. Results of Brightness Discrimination Experiments Using the Method of Constant Stimuli and the Descending Method of Limits. [Predictions from Analyses: $M_{M C S}<M_{D} ; \sigma_{M C S}>\sigma_{D}$ when c is amall.]

Statistical Measure in Log $\mathrm{mL}$

\begin{tabular}{cccccc}
\cline { 3 - 6 } Observer & Session & $\mathrm{M}_{\mathrm{MCS}}$ & $\mathrm{M}_{\mathrm{D}}$ & $\sigma_{\mathrm{MCS}}$ & $\sigma_{\mathrm{D}}$ \\
\hline \multirow{2}{*}{ A.L. } & A.M. & -.281 & -.207 & .060 & .027 \\
& P.M. & -.251 & -.192 & .087 & .021 \\
J.D. & A.M. & -.347 & -.298 & .098 & .093 \\
\hline
\end{tabular}

light) was added to the whole adapting field.

Each session consisted of 260 judgments: 120 with one procedure, 120 with another, and 20 randomly inserted "catch tests." Table 2 summarizes the procedures. In Experiment 1, the ascending and descending series were alternated randomly. In Experiment 2, 60 judgments were made with the large-step size, then 120 with the small-step size, then 60 with the large-step size, in the morning session; the order was reversed in the afternoon session. In Experiment 3, 60 judgments with the DML were followed by 120 judgments with the MCS and then by 60 judgments with the DML in the a.m. session; the order was reversed in the p.m. session.

\section{Results}

The results of the experiments, along with predictions appropriate to each experiment, are presented in Tables 3, 4, and 5. Except for the MCS part of Experiment 3, the predictions are based on the assumption that the $p$ values form an unspecified cumulative symmetrical distribution. The means and standard deviations for the ML procedures were computed in the usual way. In Experiment $3, \mathrm{M}_{\mathrm{MCS}}$ and $\sigma_{\mathrm{MCS}}$ were estimated from a straight line fitted, by the method of least squares, to a plot of $\log \Delta \mathrm{Is}$ vs proportion of "Yes" responses (a MCS plot) plotted on a cumulative normal scale. In all "catch tests," the Os responded correctly.

In Experiment 1, excluding the prediction $\sigma_{A}=\sigma_{D}, 15$ of the 16 evaluations support the predictions. In Experiment 2, 7 of the 8 evaluations support the predictions. In Experiment 3, all 8 evaluations support the predictions. In short, in spite of all the 
practical limitations, the data support the predictive value of the analyses.

If the cumulative normal distribution is assumed to be the underlying distribution, Eqs. 18, 19, 21, 22, and 23 may be used to estimate $\mathbf{M}_{M C S}$ and $\sigma_{M C S}$ from the data given in Tables 3, 4, and 5. For example, for O J.D., for the morning session of Experiment 2 (see Tables 2 and 4 ) for the large-step size: $c=.12$, $\mathrm{M}_{\mathrm{D}}=-.379$, and $\sigma_{\mathrm{D}}=.093$. Applying Eq. 19:

$$
\mathrm{M}_{\mathrm{MCS}}=-.379-.637(.093)+.337(.12)=-.398 \text {. }
$$

Also, using Eq. 22:

$$
\sigma_{\mathrm{MCS}}=1.56(.093)-.382(.12)=.099
$$

An alternative method ${ }^{8}$ for estimating $M_{M C S}$ and $\sigma_{M C S}$ is to treat the ML data like MCS data, i.e., calculate the proportion of "Yes" responses at each stimulus value, plot the proportion of "Yes" responses vs stimulus values (a MCS plot), and estimate $M_{M C S}$ and $\sigma_{M C S}$ from the plot. This procedure was followed for the example just discussed. The data points, plotted on a cumulative normal scale, were fitted, by the method of least squares, with a straight line. The estimates obtained were: $\mathrm{M}_{\mathrm{MCS}}=-.420$, and $\sigma_{\mathrm{MCS}}=.132$.

\section{REFERENCES}

DIXON, W. J., \& MOOD, A. M. A method for obtaining and analyzing sensitivity data. Joumal of the American Statistical Association, 1948, 43, $109-126$.

GUILFORD, J. P. Psychometric methods (2nd ed.) New York: McGraw-Hill, 1954.

HERRICK, R. M. Psychophysical methodology: Comparison of thresholds of the method of limits and of the method of constant stimuli. Perceptual \& Motor Skills, 1967, 24, 915-922.
HERRICK, R. M. Relationships among assumptions of the method of limits and the method of constant stimuli. AMRD, U.S. Naval Air Development Center, Johnsville, Pa. Report MR-6801, 38 pps., 1968.

HERRICK, R. M. Psychophysical methodology: Comparisons within the method of limits. Perceptual \& Motor Skills, 1969, 28, 503-5 14.

POLLACK, I. Computer simulation of threshold observations by method of limits. Perceptual \& Motor Skills, 1968, 26, 583-586.

SIEGEL, M. H. Discrimination of color. I. Comparison of three psychophysical methods. Journal of the Optical Society of America, $1962,52,1067-1070$.

URBAN, F. M. The application of statistical methods to the problems of psychophysics. Philadelphia: Psychological Clinic Press, 1908.

\section{NOTES}

1. Address: Aerospace Medical Research Department, Naval Air Development Center, Johnsville, Warminster, Pennsylvania 18974.

2. Some discussion of nonprobability influences may be found in an earlier publication (Herrick, 1969).

3. Other definitions of the threshold have been considered elsewhere (Herrick, 1969).

4. The points discussed in this paragraph are considered more fully elsewhere (Herrick, 1968).

5. Following the ideas presented in the first paper of this series (Herrick, 1967), Pollack (1968) performed Monte Carlo simulations of various psychophysical procedures. The results of his simulations differ slightly from the results obtained with Eqs. 9-13. The discrepancies undoubtedly result from some minor errors in the computer simulation process, noted by Pollack.

6. Over a wider range, from $c^{\prime}=0.10$ to $c^{\prime}=2.667$, the relationship may be described by the more complex equation, $z=-.28+4.04\left(\mathrm{c}^{\prime}\right)^{-.84}$.

7 . Over the range from $c^{\prime}=0.10$ to $c^{\prime}=2.667$, the equation, $\sigma_{\mathrm{A}}^{\prime}=.92\left(\mathrm{c}^{\prime}\right)^{2.2}$, gives a good approximation.

8. This method is discussed and illustrated in an earlier paper (Herrick, 1969).

(Accepted for publication May 12, 1969.) 